\title{
English Language Training Curriculum: An Evaluation from Learner's Perceptions
}

\author{
Thai Do Le ${ }^{1}$, Thanh Ngoc Thien Tran² \\ ${ }^{1}$ Faculty of Foreign Languages, An Giang University, Long Xuyen, Vietnam \\ ${ }^{2}$ Academic Office, ILA Rach Gia, Rach Gia, Vietnam \\ Email: ldthai@agu.edu.vn, thienthanhlx123@gmail.com
}

How to cite this paper: Le, T. D., \& Tran, T. N. T. (2021). English Language Training Curriculum: An Evaluation from Learner's Perceptions. Open Journal of Social Sciences, 9, 40-57.

https://doi.org/10.4236/jss.2021.93004

Received: February 7, 2021

Accepted: March 7, 2021

Published: March 10, 2021

Copyright ( 2021 by author(s) and Scientific Research Publishing Inc. This work is licensed under the Creative Commons Attribution International License (CC BY 4.0).

http://creativecommons.org/licenses/by/4.0/

\begin{abstract}
This study aimed to investigate EFL students' perceptions of an English language training curriculum for English language majors at a university in Vietnam. The participants included one hundred attendants of the English language courses in the curriculum. The data were collected through questionnaires and semi-structured interviews. The study results reveal that five components of the English language training curriculum for English language majors at the university (including objective, content, material, teaching method, and assessment) have not yet been done at optimum, as perceived by the students. The participants also suggest making certain modifications in the five components of the curriculum to make it more effective and better adjusted to the learners' needs. Several important implications and recommendations relevant to the field have also been included.
\end{abstract}

\section{Keywords}

English Language Training Curriculum, Components of Training

Curriculum, Learners' Perceptions

\section{Introduction}

The word "curriculum" is derived from an ancient Latin term meaning "racecourse"; over time, it has evoked different thoughts in many educators. Tanner (1980) defined curriculum as "the planned and guided learning experiences and intended outcomes, formulated through the systematic reconstruction of knowledge and experiences under the auspices of the school, for the learners' continuous and willful growth in personal social competence" (p. 13). Meanwhile, Haas (1987) provided a broader definition, stating that a curriculum includes "all of the experiences that individual learners have in a program of education 
whose purpose is to achieve broad goals and related specific objectives, which is planned in terms of a framework of theory and research or past and present professional practice" (p. 5). On the other hand, Ornstein and Hunkins (2004) provide five different definitions for the concept of curriculum. First, a curriculum can be defined as a plan for action or a written document that includes strategies for achieving desired goals or ends. Second, a curriculum can be defined broadly-as dealing with experiences of the learner. Third, curriculum can be considered as a system for dealing with people and the processes or the organization of personnel and procedures for implementing that system. Fourth, curriculum can be viewed as a field of study. Finally, curriculum can be considered in terms of subject matter or content (ibid.).

A curriculum is the "heart" of any institution, which means that schools or universities cannot exist without a curriculum (Alvior, 2014). One of the most important prerequisites of delivering an effective and quality language education was having a clearly defined curriculum in terms of its teaching goals and specific objectives. Therefore, having a good curriculum is one of the vital steps towards achieving high quality language training (ibid.).

The English language training curriculum for English language majors at the university involved in this research presents certain specific objectives. Firstly, it is to provide students with general knowledge in the English language, social culture and English and American literature. Moreover, it trains and develops students' English communicative skills at a relatively proficient level in commonly social and professional situations, which ensures that they can achieve sufficient professional qualifications to work effectively in such professional fields as interpreting or translating, business, tourism, and so forth. Particularly, the program also equips students with effective studying skills for higher education and improving the knowledge of language capacity. Furthermore, one objective of the program is to shape students' initial thought of and research capacity for the issues of language, literature, culture and civilization of the English community. In addition, graduates have the ability to achieve the $\mathrm{C} 1$ level of English language proficiency based on the Common European Framework of Reference for Languages Level (CEFR).

However, some problems can be seen from the English language training curriculum for English language majors at this university. In reality, there have been a significant number of EFL graduates who cannot pass the language proficiency exam to get the CEFR $\mathrm{C} 1$ level and cannot use English as a means of supporting their professions, which is opposed to the objectives stated in the curriculum. As shown from the current curriculum, it can be clearly seen that it concentrates mainly on four skills of English: speaking, writing, listening and reading; but the subjects related to professional skills (i.e. in business or tourism) are limited; subjects which enable students to gain initial foundations of language research (e.g. Pragmatic, Semantics, Syntax, Morphology, or Phonetics) are selective and are taught in the very last semesters; students may even choose either to learn these important subjects or to conduct undergraduate thesis instead, which means 
that if students choose not to do these courses, they will not have any opportunities to gain in-depth knowledge of the language. It is questionable that whether English language majors may compete with graduates from other majors when they do not specialize in any fields, even ones in their specialization.

Indeed, little has been known about or researched into the English language training program for English language majors at this university and it is not clear what the strengths and weaknesses of the curriculum are. It is questionable that how much the instructors and students are satisfied with the program content, which methods teachers have employed most during lessons, whether the materials are sufficient in achieving the educational objectives and whether the assessment procedures are parallel to the instruction. The current study aims at finding out the answers to these questions.

Central to the study is the evaluation of the English language training curriculum at one university in Vietnam from the perspectives of the students. The study is conducted so as to find the answers to this following research question: What are EFL students' perceptions of the English language training curriculum for English language majors at their university? It is expected that the study findings will be able to contribute to modifying and improving the English language training curriculum at the university as well as enhancing the English teaching and learning quality at tertiary level in the future.

\section{Curriculum and Curriculum Evaluation}

\subsection{Curriculum and Its Components}

Although many researchers and curriculum specialists have given many different definitions about the word "curriculum", from the field of applied linguistics, the word "curriculum" has been proposed in a similar definition; that is, an educational program includes the educational purposes of the program, the content, teaching procedures and learning experiences which will be necessary to achieve this purpose, and some means for assessing whether or not the educational ends have been achieved (Richards, Platt and Platt, 1992). While a variety of definitions of the term "curriculum" have been suggested and this study does not contain all of the definitions of "curriculum", the definition proposed here is consistent with the tradition that views the curriculum as a systematic plan for learning, a master plan for selecting content and organizing learning experiences for the purpose of changing and developing learners' behaviors and insights.

Regarding language curriculum, as cited in the English Language Curriculum and Assessment Guide (Secondary 4 - 6) published in 2007, the overall aims of the English Language curriculum are to provide every learner of English with further opportunities for extending their knowledge and experience of the cultures of other people as well as opportunities for personal and intellectual development, further studies, pleasure and work in the English medium and to enable every learner to prepare for the changing socio-economic demands resulting from advances in information technology—demands which include the 
interpretation, use and production of texts for pleasure, study and work in the English medium.

The way a language curriculum is designed has changed through the years. According to Nation and Macalister (2010), a language course has to be designed in such a way that it covers language items, skills and strategies. In one study, Richards (2001) indicates that different aspects of a program can be the center of attention in program evaluation. They may include curriculum design, syllabuses and program content, classroom processes, materials, teachers, teacher training, students, institution, staff development or decision making. In a presentation at the Missouri Department of Elementary and Secondary Education's Powerful Learning Conference, McNulty (2013) pointed out that a curriculum had to include five main components. They are objectives; assessment; essential skills, knowledge, and attitudes; instructional tools and approaches for classroom use (see Figure 1).

As can be seen in Figure 1, the curriculum generally includes five main components: educational objectives, content, materials, teaching methods, and assessment, though there may be a variety of suggestions for the term "curriculum design" so far. The diagram shows a clear, proper view for curriculum designer and reviewer. In the scope of this current study, these five components are employed as operational ones.

The concept of educational objectives holds a central position in the literature of curriculum (Eisner, 1969). "Educational objectives" may be divided into two

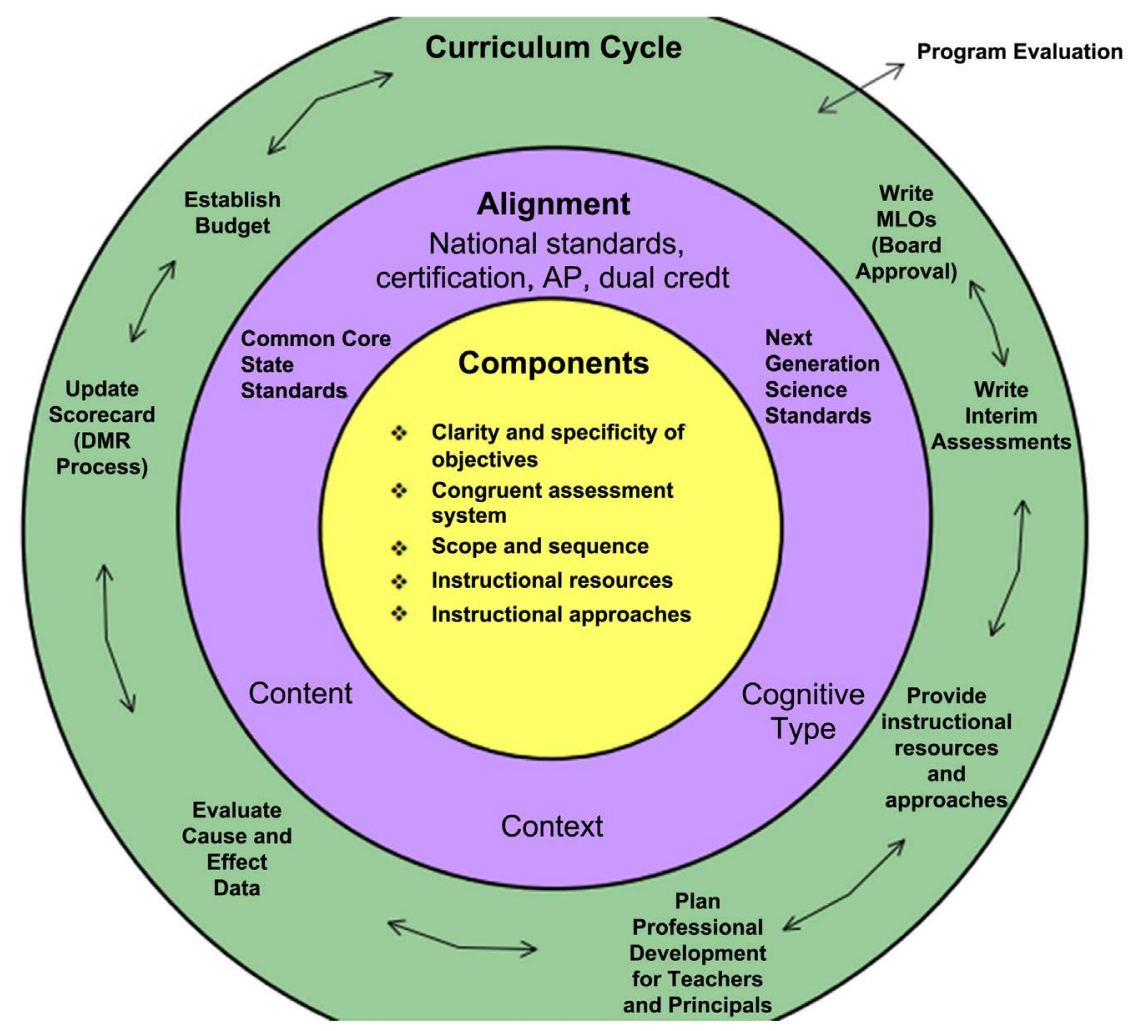

Figure 1. Curriculum design and review process (McNulty, 2013). 
divisions: instructional objectives, which emphasize the acquisition of the known (skills defined in a predictive model of curriculum development), and expressive objectives, which elaborate and modify existing knowledge (ibid.).

The component "content" consists of facts, concepts, generalizations or principles, attitudes, and skills related to the subject. Content includes both what the teacher plans for students to learn and how the student gains access to the desired knowledge, understanding, and skills (Tomlinson and Allan, 2000).

According to Goodlad (1994, as cited in Ball \& David, 1996), commercially published "curriculum materials" dominate teaching practice in the United States. They were said to be concrete and daily; unlike frameworks, objectives, assessments, and other mechanisms that sought to guide curriculum. The enacted curriculum is actually jointly constructed by teachers, students, and materials in particular contexts (Ball \& David, 1996). The definition of the component "materials" used in the study is "instructional and related or supportive material", including materials using advanced learning technology, in any occupational field that is designed to strengthen the academic foundation and prepare individuals for employment at the entry level or to upgrade occupational competencies of those previously or presently employed in any occupational field, and appropriate counseling and guidance material, which is defined in the Office of the Federal Register National Archives and Records Administration (1998, p. 8).

Miel (1956) claimed that "methods" of teaching-learning influence the content of experiences which make up the curriculum (p. 338). In the study, the component "teaching methods" is signified as the principles and methods used for instruction to be implemented by teachers to achieve the desired learning by students.

The component "assessment" contains things related to assessment, like the number of exams, the difficulty of the exams, how the students get the exams and if the exams reflect the real capacity of learners. Learners' needs may be interpreted in two different ways: what the learner will do with the language at the end of a course of study (a goal-oriented approach) or what the learner needs during the learning process (a process-oriented approach) (Widdowson, 1981 as cited in Astika, 1999).

\subsection{Curriculum Evaluation}

Regarding curriculum evaluation, it can be defined as a systematic process for collecting and analyzing all relevant information for the purpose of judging and assessing the effectiveness of the curriculum to promote improvement (e.g., Nichols et al., 2006; Simons, 1987 as cited in Marsh, 2004; Brown, 1989 as cited in Brown, 1995). Ornstein and Hunkins (1998, as cited in Nazeer, Shad and Sarwat, 2015) define "curriculum evaluation" as "a process or cluster of processes that people perform in order to get data that will enable them to decide whether to accept, change, or eliminate something-the curriculum in general or an educational textbook in particular".

Morrison (2003) claimed that no curriculum was perfect in design and deli- 
very. If the results of an evaluation show that no further development is needed, doubt is cast on the methods of evaluation or the interpretation of the results. This does not mean that curricula should be in a constant state of change, but that the results of evaluation to correct deficiencies are acted on, that methods continue to improve, and that content is updated. Then the process starts all over again (ibid.).

Imani (2013) draws our attention to the significance of having codified standards for a curriculum in specific and an educational program in general. From this point of view, she pointed out that carrying out evaluation studies in order to comprehend strengths and weaknesses of educational programs, applying modifications and determining the degree of consistency between standard educational systems and other systems in other contexts seemed to be an essential mission of every successful educational program. Furthermore, it is essential to evaluate the opinions of the EFL students and the lecturers in order to maintain a comprehensive overview of all aspects of the English language training curriculum (Kalfazade, Oran, Sekban and Tinaz, 1989). According to Al-Jardani (2012), curriculum evaluation helps to connect all other elements of curriculum and also to highlight positive and negative issues related to these elements, such as the aims, goals and purpose of different subjects, guidelines for course design, teaching and learning principles and others. Therefore, this study is carried out with the aim of investigating what English language majors' students and lecturers thought about the effectiveness of the English language training curriculum, the problems EFL students encountered as well as if this curriculum met the needs of the students.

A considerable amount of literature has been published on students' and teachers' perceptions of English language curriculum. Tunc, (2010) evaluates the effectiveness of Ankara University Preparatory School program through the perspectives of instructors and students. To this end, the CIPP (context, input, process, and product) evaluation model developed by Stufflebeam (1971) was utilized. 406 students attending the preparatory school in the 2008-2009 academic year and 12 instructors teaching in the program participated in the study. The data were gathered through a self-reported student questionnaire and an interview schedule designed for the instructors. Besides, in order to obtain more detailed information about the preparatory school, written documents were examined. While the data based on the questionnaire were analyzed through descriptive and inferential statistics, content analysis was carried out to analyze the qualitative data. Results of the study indicated that the program at Ankara University Preparatory School partially served for its purpose. The findings revealed that some improvements in the physical conditions, content, materials and assessment dimensions of the program were required to make the program more effective.

Tom-Lawyer (2014) carried out a research to evaluate the implementation of the English language curriculum of the Nigeria Certificate in Education (NCE) 
at a College of Education in Ogun State, Nigeria. Within this research setting, the certificate is the basic qualification for teaching. The poor performance of Nigerian students in external English examinations has continued to be a source of worry to parents, educational stakeholders and the government. This problem has impeded the transition to higher education of many Nigerian students. In order to proffer solution to this problem, the effectiveness of the training of English language teachers need to be examined. The study sought to fill the gap by evaluating the implementation of the English language curriculum of the NCE in order to determine the effectiveness of the schooling of teachers. In investigating these issues, a mixed methods approach was used to conduct a case study. The sample comprised ten lecturers and twenty students drawn through convenience sampling techniques. The instruments were questionnaires, observation checklists, interviews and field notes. The methods of analysis were descriptive/inferential statistics and thematic content analysis. The findings revealed that lecturers employed mostly a combination of teaching modes in classrooms. The resources (physical and human) were found to be inadequate and the school technologically deficient. Furthermore, the negative attitudes of the students impacted on the implementation of the curriculum. The study identified the ineffective implementation of the NCE English language curriculum. The paper recommends that parents and other stakeholders should thoroughly investigate teacher training.

Saito and Ebsworth (2004) investigate how college-level Japanese English language learners in English as a second language (ESL) and English as a foreign language (EFL) context viewed their English teachers and classroom activities. Analysis of 100 questionnaires incorporating quantitative and qualitative questions revealed that most Japanese students positively viewed teachers who were open, respectful of other cultures, and willing to adjust classroom content to meet students' needs. Among the differences between ESL and EFL students were ESL students' greater comfort with active participation in class, more time spent in class, physical proximity to teachers, and appreciation of student-centered behavior. On the other hand, EFL students appreciated teachers who provided native language support and avoided possible loss of face entailed by challenging and unexpected questions.

\subsection{Justification of the Study}

In conclusion, it can clearly be seen that a curriculum is considered as a systematic plan for learning, for selecting content and organizing learning experiences for the purpose of changing and developing learners' behaviors and insights, which cannot be overlooked at any universities. It is essential to look closely at the opinions of the EFL students in order to maintain a comprehensive overview of all aspects of the English language training curriculum (Kalfazade, Oran, Sekban and Tinaz, 1989 as cited in Tunc, 2010). Therefore, investigating EFL students' perceptions is necessarily important to improve the language training program; however, there have been very few studies carried out so far, espe- 
cially in the context of tertiary education, which led to the implementation of this study.

\section{Research Design and Methods}

This descriptive study aims to evaluate the English language training curriculum at a university in Vietnam from the perspectives of students. Both qualitative and quantitative data were collected. Regarding the quantitative data, a self-reported questionnaire consisting of two sections was used to collect data from EFL students. The qualitative data were gathered through interviews conducted with EFL students at the university and through the open-ended questions in the questionnaires.

\subsection{Research Participants}

The participants in this study comprised of $100 \mathrm{EFL}$ students studying English Language at a university in Vietnam, with age ranging from 18 to 25 . They are senior, junior, and sophomore students, all of whom are required to study in the same curriculum. They are taking the four-year English language training curriculum at the university. Overall, they attend several English language courses in their first three academic years, which mainly focused on improving their four language skills (i.e., Listening, Speaking, Reading, Writing, and Translation) and certain linguistic aspects like Pronunciation and Grammar. In the last year at the university, they are taught specialized subjects such as Pragmatics, Semantics, Syntax, Morphology, or Phonology. Briefly, most specialized courses on linguistics are scheduled in the last year at university and many of them are selective.

\subsection{Research Design}

- The questionnaire was specially designed for gaining insights into the students' perceptions of the English language training curriculum for English language majors at the university, with a set of 40 questions. The response options for each question in the survey were rated according to a five-point Likert scale: Strongly disagree, Disagree, No ideas, Agree, and strongly agree. The questionnaire includes items about the content, teaching methods, materials, educational objectives and assessment applied in the curriculum (25 items), along with those in relation to the expectations of EFL students about the curriculum (15 items). The items of the questionnaire were adapted based on the theory of the previous studies of Erozan et al. (2006), Coskun and Daloglu (2010) and Tunc, (2010). Prior to being administered, the questionnaire underwent many changes in terms of wording and meaning for its validity. Finally, in the main scheme students were asked to complete the questionnaires in the classroom. To ensure the reliability of student's responses the research, clear instructions were given before the questionnaires were delivered to 100 student participants. 
- The interview was administered to gain in-depth information on students' perceptions and expectations about the English language training curriculum for English language majors at the university. The interview questions covered two main issues related to teaching and learning with the English language training curriculum for English language majors. They are perceptions and expectations of students about five components of the curriculum. The participants of the interview were $15 \mathrm{EFL}$ students studying in the third and last academic year.

\subsection{Data Analysis}

- The data collected through the questionnaire were compiled and the IBM SPSS Statistics 20.0 program was employed to analyze the data. In the piloting process, the researcher used SPSS to analyze the reliability of the data obtained from the ten students; the result was shown in Table 1 as follows: After passing the piloting of the instrument, the researcher continued giving 100 other EFL students the questionnaires and still used SPSS to analyze the data.

- The analysis for the interviews involved descriptive data as well. Note-taking technique was used. All the answers of the interviewees were analyzed by categorizing the points that came out from the statements for each question. In addition, thematic analysis and grouping of the answers from different interviewees to the same or similar questions were employed for the analysis of interviews. The content analysis was carried out. Answers from different interviewees to common questions were categorized under five components of the curriculum.

\section{Results and Discussions}

The central question of this study is to examine what EFL students' overall perceptions of the English language training curriculum for English language majors at the university are. The Cronbach's alpha coefficient for 25 items was 0.91 (see Table 2), suggesting that all the items of the questionnaire had very high internal consistency.

The questions in the questionnaire aimed to gather data related to five components of the curriculum: 1) content, 2) methods, 3) materials, 4) objective, and 5) assessment. The results of the program evaluation analyzed by the Descriptives Test are summarized in Table 3, as below:

The one-sample T-test was run on the test value 4.0 and the mean score of students' perceptions of the language training program for English language majors at the university. The result (see Table 4) shows that there was a significant difference between the mean score $(M=3.59)$ of students' evaluation of the issue and the test value $4.0(\mathrm{t}=-6.83 ; p=0.00)$. It means that though EFL students' perceptions were inclined to be more positive than negative, they still remained neutral attitudes toward the curriculum. 
Table 1. Reliability statistics of the pilot study.

\begin{tabular}{cc}
\hline \multicolumn{2}{c}{ Reliability Statistics } \\
\hline Cronbach's Alpha & N of Items \\
0.878 & 40 \\
\hline
\end{tabular}

Table 2. Reliability statistics of the major instrument.

\begin{tabular}{ccc}
\hline & Reliability Statistics \\
\hline Cronbach's Alpha & $\begin{array}{c}\text { Cronbach's Alpha } \\
\text { Based on Standardized Items }\end{array}$ & N of Items \\
0.911 & 0.912 & 40 \\
\hline
\end{tabular}

Table 3. EFL students' overall perceptions of the curriculum.

\begin{tabular}{cccccc}
\hline Variable & N & Min. & Max. & Mean & SD \\
\hline Perceptions & 100 & 1.16 & 4.92 & 3.59 & 0.60 \\
\hline
\end{tabular}

Table 4. Result of one-sample T-test.

\begin{tabular}{cccc}
\hline Variable & $\mathbf{t}$ & $\mathrm{df}$ & Sig. \\
\hline Perceptions & -6.83 & 99 & 0.00 \\
\hline
\end{tabular}

Further investigation was conducted to investigate how different it was among students' perceptions of each component of the curriculum, the Descriptive Test was run on the mean scores of students' perceptions of each component of the curriculum. The results are summarized in Table 5 below.

The Pair Sample T-Test was run on the mean score of Content, Material and Objective. The results show that there is no difference $(\mathrm{t}=-1.66, p=0.10)$ between the mean score of Content $(\mathrm{M}=3.34, \mathrm{SD}=0.82)$ and Material $(\mathrm{M}=3.44$, $\mathrm{SD}=0.79)$. Regarding the students' perceptions of Content and Objective, the mean scores $(\mathrm{M}=3.34, \mathrm{SD}=0.82 ; \mathrm{M}=3.37, \mathrm{SD}=0.82$, respectively) have no difference $(\mathrm{t}=-0.50, p=0.62)$. The mean score of Material $(\mathrm{M}=3.44, \mathrm{SD}=$ $0.79)$ is similar ( $\mathrm{t}=0.91, p=0.37)$ to that of Objective $(\mathrm{M}=3.37, \mathrm{SD}=0.82)$. The results support the conclusion that while the students held positive perceptions of lecturers' teaching methods and the assessment of the curriculum, they were not highly satisfied with its content, teaching materials and educational objectives.

\subsection{Content}

The data from the Table 5 indicates that EFL students held neutral position about the content of the language training program for English language majors at the university (Mean $=3.34$ ). The data also reveals that there is a rather big difference in their perceptions of the program content among the students $(\mathrm{SD}=$ $0.82)$

Looking further into the difference in the EFL students' perceptions of the 
Table 5. EFL students' perceptions of each component of the curriculum.

\begin{tabular}{cccccc}
\hline Variable & N & Min. & Max. & Mean & SD \\
\hline Content & 100 & 1.00 & 5.00 & 3.34 & 0.82 \\
Method & 100 & 1.00 & 5.00 & 4.03 & 0.68 \\
Materials & 100 & 1.00 & 4.80 & 3.44 & 0.79 \\
Objective & 100 & 1.00 & 5.00 & 3.37 & 0.82 \\
Assessment & 100 & 1.00 & 5.00 & 3.77 & 0.69 \\
\hline
\end{tabular}

program content, the One-Way ANOVA was run on the mean scores of students' perceptions of the program content to 3 classes 14TA $(M=2.94)$, 15TA $(\mathrm{M}=3.58)$ and $16 \mathrm{TA}(\mathrm{M}=3.73)$. It can be seen that there is an enormous difference between these groups $(p=0.00)$ (see Table 6). While the sophomores had a quite positive attitude towards the content, the seniors remained neutral about this component.

Likewise, when being interviewed about the balance of the theory and the practice components of the program, most of the student respondents (12 out of 15) said "not balanced yet". On the other hand, one respondent felt the theory and practice components of the program were quite balanced because some activities like presentations, group work or role-play made up approximately $60 \%$ to $70 \%$ of the amount of class time.

\subsection{Teaching Methods}

This part of the questionnaire aimed at investigating what EFL students thought about the teaching methods used in the classes. The Descriptives Test was run out and the result (see Table 5) shows that most of EFL students expressed highly positive attitudes toward the teaching methods used in the classes $(\mathrm{M}=$ $4.03, \mathrm{SD}=0.68$ ). After that, the One-way ANOVA was run to clarify whether students at different classes have various thought on the teaching methods; the results show that there is no difference among students at all classes $(p=0.37)$, concluding that students hold positive perceptions of this component of the curriculum regardless of their academic levels (see Table 7).

Next, the researcher used the Descriptives Test with the aim of investigating the extent to which teaching methods were employed in class. It can be clearly seen that no activity was used as much as "pair/group work" (see Table 8). On the other hand, teachers seldom assign students "role-play".

Parallel to the results of the questionnaire, most of the respondents (12/15 students) asked to give their opinions about the teaching methods used in the lessons, especially "pair/group work", were satisfied with its effectiveness. However, one respondent felt satisfied with the group work, but not with pair work, and the other respondents said that she did not enjoy working in group.

\subsection{Teaching Materials}

This section aimed at evaluating the sufficient level of materials used during lessons. 
Table 6. Students' perceptions of the content of the curriculum.

\begin{tabular}{cccccc}
\hline & Sum of Squares & df & Mean Square & F & Sig. \\
\hline Between Groups & 12.57 & 2 & 6.28 & 11.22 & 0.00 \\
Within Groups & 54.31 & 97 & 0.56 & & \\
Total & 66.87 & 99 & & & \\
\hline
\end{tabular}

Table 7. Students' perceptions on teaching methods.

\begin{tabular}{cccccc}
\hline & Sum of Squares & Df & Mean Square & F & Sig. \\
\hline Between Groups & 0.92 & 2 & 0.46 & 1.01 & 0.37 \\
Within Groups & 44.44 & 97 & 0.46 & & \\
Total & 45.36 & 99 & & & \\
\hline
\end{tabular}

Table 8. Teachers' teaching methods used in the classroom.

\begin{tabular}{cccccc}
\hline & N & Min. & Max. & Mean & SD \\
\hline Pair/group work & 100 & 1.00 & 5.00 & 4.42 & 0.83 \\
Presentations & 100 & 1.00 & 5.00 & 4.19 & 0.87 \\
Lecturing & 100 & 1.00 & 5.00 & 4.04 & 0.93 \\
Questions & 100 & 1.00 & 5.00 & 3.99 & 0.96 \\
Role-play & 100 & 1.00 & 5.00 & 3.50 & 1.01 \\
\hline
\end{tabular}

As seen from Table 5, most students remained neutral attitudes toward materials used during lessons (Mean $=3.44, \mathrm{SD}=0.79$ ).

In order to examine whether the three groups of students had similar perceptions of materials of the program or not, the One-way Anova was run and the results (see Table 9$)$ show that the seniors $(\mathrm{M}=3.14)$ had enormously different perceptions of materials $(p=0.00)$ compared with juniors $(\mathrm{M}=3.66)$ and sophomores $(M=3.68)$. It is concluded that seniors rated the materials of the program lower than sophomores and juniors.

In addition to data obtained from the questionnaire, the researcher kept on interviewing respondents. As being asked to evaluate the course materials, they pointed out both the strengths and the weaknesses of them. Most of the respondents (12/15 students) felt the materials were unattractive and boring. One of them also expressed that although some textbooks of some subjects were so boring due to full of words, she felt excited at the textbooks of some subjects related to culture and history (i.e., tourism, American studies). On the other hand, one respondent was satisfied with the materials because they helped her widen her knowledge.

\subsection{Objectives}

The questionnaire includes a section of the educational objectives of the language training program. This part of the questionnaire was composed of 5 items 
listed in Chapter 3. The data from the Table 5 indicates that EFL students kept neutral attitudes toward these objectives $(\mathrm{M}=3.37, \mathrm{SD}=0.82)$.

Looking further into the difference in the EFL students' perceptions of the program objectives, the One-Way ANOVA was run on the mean scores of students' perceptions of the program objectives according to the 3 groups of students: seniors $(M=2.95)$, juniors $(M=3.48)$ and sophomores $(M=3.97)$. It can be seen clearly from Table 10 that there is a dramatic difference among these groups $(p=0.00)$, meaning that the sophomores rated this component at much higher level than the juniors and the seniors.

The interviews conducted with students reveals that the curriculum did not meet their needs for working effectively in business after graduation (15/15 students) and all of them felt this objective was not feasible.

Through the interview with students about their perceptions of the objectives of the program for English language majors at the university, it is concluded that they were not trained expertly to achieve sufficient professional qualifications to work effectively in such professional field as business. Furthermore, students who had their own clearly orientation for their future job had to study subjects in contrast with their expectation.

\subsection{Assessments}

In the course evaluation, the students were asked to evaluate assessment in the language training program for English language majors. The results summarized in Table 5 indicated that students were inclined to be relatively positive in the assessment $(M=3.77, S D=0.69)$. Next, the One-way ANOVA was run to clarify whether students at different classes have various thoughts on the assessment, showing that there is significant difference among students at all classes ( $p=$ $0.00)$ (see Table 11). It can be concluded that whereas juniors $(M=3.98)$ and sophomores $(M=4.03)$ were satisfied with the assessment of the program, the seniors evaluated it in a less positive way $(\mathrm{M}=3.46)$.

When being asked whether students were assessed on the things they practiced

Table 9. Students' perceptions of teaching materials.

\begin{tabular}{cccccc}
\hline & Sum of Squares & Df & Mean Square & F & Sig. \\
\hline Between Groups & 6.85 & 2 & 3.42 & 6.30 & 0.00 \\
Within Groups & 52.70 & 97 & 0.54 & & \\
Total & 59.55 & 99 & & & \\
\hline
\end{tabular}

Table 10. Students' perceptions on educational objectives.

\begin{tabular}{cccccc}
\hline & Sum of Squares & df & Mean Square & F & Sig. \\
\hline Between Groups & 16.89 & 2 & 8.45 & 16.76 & 0.00 \\
Within Groups & 48.90 & 97 & 0.50 & & \\
Total & 65.79 & 99 & & & \\
\end{tabular}


Table 11. Students' perceptions on assessment.

\begin{tabular}{cccccc}
\hline & Sum of Squares & Df & Mean Square & F & Sig. \\
\hline Between Groups & 7.22 & 2 & 3.61 & 8.79 & 0.00 \\
Within Groups & 39.83 & 97 & 0.41 & & \\
Total & 47.04 & 99 & & & \\
\hline
\end{tabular}

in the lessons, all respondents (5/5 students) are in agreement. On the other hand, one of the respondents stated that there was a difference in the results between tests in class and final exams.

\section{Conclusion}

\subsection{EFL Students' Overall Perceptions of the Language Training Program for English Language Majors at the University}

The findings of the questionnaire show that EFL students tended to be satisfied with the language training program for English language majors, but they still remained their neutral positions. The results of the student questionnaires and interviews showed that the students expressed positive attitudes toward the teaching methods and assessment of the program and that they evaluated the program content, materials and objectives in a less positive way.

In terms of the first component of the program, students' reflections about the program content corroborates with findings of evaluation study done in Turkey (Coskun and Daloglu, 2010). Most of the students expressed that the theory and practice of the program had not been balanced yet and most of the lecturers felt the length of the courses were so limited.

Regarding the types of teaching methods used during lessons, the questionnaire results of the students and the instructors' interview showed parallel perceptions, which show that no activity was used as much as "pair/group work". Inconsistently, whereas Tunc, (2010) indicated that the mostly used type of instructional method and Tom-Lawyer (2014) recommended the best method was lecturing, the findings from the questionnaire show that no activity was used as much as "pair/group work" in the classes.

According to Sheldon (1987), materials are evaluated not only by teachers and reviewers, but also by educational administrators charged with obtaining the best textbook value for money. Consistently, most of the participants claimed that the course books which had been consulted from many universities were chosen selectively and updated regularly by the lecturers. However, most of EFL students kept neutral attitudes toward the materials used during the course. This is in line with a study conducted by Erozan et al. (2006), which indicated that despite the usefulness of the materials, students did not believe that they were fully sufficient for improving their English skills. Moreover, the majority of EFL students expressed in the interviews that the materials were not attractive and interesting due to many reasons: full of words, lack of illustratable images, lack of diverse and attractive tasks. 
The findings also indicate that the students were not trained expertly to achieve sufficient professional qualifications to work effectively in professional fields (e.g., business, tourism, as an editor-translator) after graduation. Furthermore, it is indicated that the present objectives were not fully practical and feasible.

Lastly, concerning the assessment of the program, there are similarities between the attitudes expressed by EFL students and those described by Erozan et al. (2006) in that exams were in line with classroom practice and the test results do not reflect students' actual ability due to many reasons (i.e., luckiness, teachers gave some plus marks to encourage students and so forth). It is vital to note from this study that the assessment form of some subjects was not suitable, and the scoring method was perceived not highly fair because there was a big difference in scoring between the teachers who taught that subject and the teachers who did not.

\subsection{Implications of the Study}

The findings from the research can carry important implications for improving the curriculum for English language majors at university. The findings show that the majority of students had positive attitudes toward the teaching methods and the assessment of the program. On the whole, they were satisfied with the teaching methods used during the lessons (i.e., pair/group work) and they claimed that they were assessed in accordance with what they practiced in the lessons, which should be maintained. However, most of the students were not satisfied with the whole curriculum, particularly its content, materials and objectives, which means that the whole program needs to be accordingly tailored.

In order to fulfill the participants' needs for the balance of the theory and practice of the program, it is recommended that the amount of time for courses taught by English native speakers be increased and that the university give students more opportunities to practice their English skills as well as their soft skills, especially through field trips. The university should also carry out a survey to explore the students' career orientation as well as the courses they truly expect to do so that the program could supplement its objectives as well as the subjects which meet their expectations. The program should also reduce the number of obligatory subjects so as to leave room for selective ones. As for handling the problem related to the materials used during the course, lecturers could carry out a survey to see students' expectations of that subject, then make best use of many good sources to compile the major course book instead of applying any single coursebooks. Furthermore, the university should equip a room which is only used to teach listening skills, a soundproof room with tables equipped laptops and headphones, and projectors for classrooms should be available as required.

Another important practical implication is that the educational objectives of the program for English language majors were not practical and feasible. Thus, the program objectives could be more flexible, aiming at helping the learners not 
only achieve a certain language proficiency level but obtain their desirable vocations as well.

Concerning the assessment, the evidence from this study suggests that the university should let instructors petition the assessment form of the subjects they are teaching, and the detailed scoring standards should be published as soon as possible for instructors to prepare for the exam. Also, the university should consider the assessment form of some subjects and adjust the grading score method more detailed.

\subsection{Recommendations for Further Studies}

Although the study reached its aims, there were certain unavoidable shortcomings. Firstly, this evaluation study is only based on students' subjective perceptions about the program in one university in Vietnam, which could not have pointed out all the strengths and weaknesses of the English language curriculum. Secondly, the study is conducted on a small scale of participants, just 100 students, which may, to some extent, have influenced the generalization of the study. What's more, the date was collected solely from the current students, but not from alumni of the program, which could have been analyzed to see whether the program has met students' needs as its initial specific objectives or not. Lastly, the major limitation of the study is the broad scope of the study. The researcher evaluated the whole curriculum, so the findings of the study were not detailed.

This study has thrown up many questions in need of further investigation. Firstly, to avoid the subjective information, more objective data could have been gathered if classroom observations of participants had been made or employers of the program graduates and other stakeholders had also participated in the study. Secondly, in future investigations, it might be possible to examine a larger sample of participants to obtain more data. Furthermore, as suggested by Tunc, (2010), the researcher may collect data from graduates of the program and future studies may focus on a comparative analysis between perceptions of the graduates and their comparison with the current ones. Lastly, aforementioned in the previous section, the scope of the study is too broad. Future research should therefore concentrate on the investigation of EFL students and lecturers' perceptions of each of the program components instead of the whole curriculum.

\section{Conflicts of Interest}

The authors declare no conflicts of interest regarding the publication of this paper.

\section{References}

(2007). English Language Curriculum and Assessment Guide (Secondary 4-6). Hong Kong: Govt. Logistics Dept.

Al-Jardani, K. S. (2012). English Language Curriculum Evaluation in Oman. International Journal of English Linguistics, 2, 40. https://doi.org/10.5539/ijel.v2n5p40 
Alvior, M. G. (2014). The Meaning and Importance of Curriculum Development. http://simplyeducate.me/2014/12/13/the-meaning-and-importance-of-curriculum-dev elopment

Astika, G. (1999). The Role of Needs Analysis in English for Specific Purposes. TEFLIN Journal, 10, 31-47.

Ball, D. L., \& David, K. C. (1996). Reform by the Book: What Is-Or Might Be-The Role of Curriculum Materials in Teacher Learning and Instructional Reform? Educational Researcher, 25, 6-8. https://doi.org/10.2307/1177151

Brown, J. D. (1995). The Elements of Language Curriculum: A Systematic Approach to Program Development. Boston, MA: Heinle ELT.

Coskun, A., \& Daloglu, A. (2010). Evaluating an English Language Teacher Education Program through Peacock's Model. Australian Journal of Teacher Education, 35, Article 2. https://doi.org/10.14221/ajte.2010v35n6.2

Eisner, E. W. (1969). Instructional and Expressive Educational Objectives: Their Formulation and Use in Curriculum. Instructional Objectives, AERA Monograph No. 3, Chicago, IL: Rand McNally.

Erozan, F., Shibliyev, J., \& Daloglu, A. (2006). Program Evaluation Revisited: Language Improvement Courses. München: LINCOM Europa.

Hass, G. (1987). Curriculum Planning: A New Approach. Boston: Allyn and Bacon.

Imani, S. S. (2013). Evaluation of Modular EFL Educational Program (Audio-Visual Materials Translation \& Translation of Deeds \& Documents). English Language Teaching, 6, 8. https://doi.org/10.5539/elt.v6n4p8

Kalfazade, N., Oran, N., Sekban, M., \& Tinaz, P. (1989). Research Conducted at Marmara University on Student Opinion on English-Medium Education and Preparatory School Education. İstanbul: Marmara Üniversitesi Yabancı Diller Eğitim ve Öğretim Araştırma ve Uygulama Merkezi, yayın No.: 89/6.

Marsh, C. J. (2004). Key Concepts for Understanding Curriculum. London: Falmer Press. https://doi.org/10.4324/9780203326893

McNulty, T. (2013). Standardized Clients in Case-Based Simulation: Five Years of Development in an Occupation-Based Curriculum. The American Occupational Therapy Education Summit, Atlanta, October 2013.

Miel, A. (1956). A View of Curriculum Content. Educational Leadership.

Morrison, J. (2003). ABC of Learning and Teaching in Medicine: Evaluation. BMJ, 326, 385-387. https://doi.org/10.1136/bmj.326.7385.385

Nation, I. S., \& Macalister, J. (2010). Language Curriculum Design. New York: Routledge. https://doi.org/10.4324/9780203870730

Nazeer, M., Shah, S. K., \& Sarwat, Z. (2015). Evaluation of Oxon English Textbook Used in Pakistan Public Schools for 6th \& 7th Grade. Journal for the Study of English Linguistics, 3, 51-79. https://doi.org/10.5296/jsel.v3i1.7778

Nichols, B., Shidaker, S., Johnson, G., \& Singer, K. (2006). Managing Curriculum and Assessment. A Practitioner's Guide. Worthington, $\mathrm{OH}$ : Linworth Books.

Ornstein, A. C., \& Hunkins, F. P. (2004). Curriculum: Foundations, Principles, and Issues. Upper Saddle River, NJ: Pearson.

Richards, J. C. (2001). Curriculum Development in Language Teaching. Cambridge: Cambridge University Press.

Richards, J. C., Platt, J., \& Platt, H. (1992). Longman Dictionary of Language Teaching and Applied Linguistics (2nd ed.). London: Longman. 
Saito, H., \& Ebsworth, M. E. (2004). Seeing English Language Teaching and Learning through the Eyes of Japanese EFL and ESL Students. Foreign Language Annals, 37, 111124. https://doi.org/10.1111/j.1944-9720.2004.tb02178.x

Sheldon, L. E. (1987). ELT Textbooks and Materials: Problems in Evaluation and Development. Oxford: Modern English Publications in Association with the British Council.

Stufflebeam, D. L. (1971). The Relevance of the CIPP Evaluation Model for Educational Accountability. Journal of Research and Development in Education, 5, 19-25.

Tanner, D. (1980). Curriculum Development: Theory into Practice. Nueva York: McMillan.

Tom-Lawyer, O. (2014). An Evaluation of the English Language Curriculum of the Nigeria Certificate in Education: A Case Study of a College of Education. Open Journal of Social Sciences, 2, 69-79. https://doi.org/10.4236/jss.2014.27011

Tomlinson, C. A., \& Allan, S. D. (2000). Leadership for Differentiating Schools \& Classrooms. Heatherton: Hawker Brownlow Education.

Tunc, F. (2010). Evaluation of an ELT Program at a Public University Using CIPP Model. Saarbrucken: Lambert Academic Publishing. 